\title{
Mudanças Institucionais e Produção Familiar na Cadeia Produtiva do Leite no Oeste Catarinense
}

\author{
Luis Fernando Tividini Oliveira ${ }^{1}$ e Sandro Pereira Silva ${ }^{2}$
}

Resumo: Este trabalho tem como objetivo geral analisar como os agricultores familiares comportam-se frente às mudanças significativas no ambiente institucional da cadeia produtiva do leite a partir de novas legislações. Nesse sentido, foram investigadas as principais consequências e impactos na organização socioprodutiva das famílias produtoras de leite na região Oeste Catarinense em decorrência da Instituição Normativa n. 51 do Ministério da Agricultura. Para tanto, foi utilizada a abordagem da Nova Economia Institucional (NEI), especialmente no que tange à formação e adaptação dos agricultores ao ambiente institucional da cadeia leiteira. A metodologia utilizada foi o estudo de caso, e as informações analisadas foram obtidas através de pesquisa de campo junto a atores estratégicos envolvidos na produção de leite e derivados na região. Concluiu-se que a IN51 influencia decisivamente a forma de organização e participação da agricultura familiar na cadeia produtiva do leite.

Palavras-chaves: Ambiente institucional, agricultura familiar, cadeia produtiva do leite, Pronaf, IN51.

\begin{abstract}
This paper aims to analyze how family farmers behave facing significant changes in the institutional environment of milk production chain. In this sense, we investigated main consequences and impacts on the social and productive organization of milk producing families as a result of the Institution Normative 51 by Ministry of Agriculture in the western region of Santa Catarina state. We used the approach of New Institutional Economics (NIE) and field research with strategic actors involved in the dairy production in the region. We concluded that the IN51 decisively influences the form of organization and participation of family farming in the milk production chain.
\end{abstract}

Key-words: Institutional environment, family farming, milk production chain, Pronaf, IN51.

Classificação JEL: A14; O18; R53.

\footnotetext{
1 Mestre em Extensão Rural pela Universidade Federal de Santa Maria. E-mail: luis.tividini@mda.gov.br

2 Doutorando em Ciências Sociais pela Universidade de Brasília. E-mail: sandroecbr@yahoo.com.br
} 


\section{Introdução}

A cadeia produtiva do leite no Brasil tem experimentado mudanças consideráveis e transformações técnicas, operacionais e institucionais, sobretudo a partir dos anos finais da década de 1990, através de inúmeras alterações nas estratégias e políticas governamentais desenvolvidas ou aplicadas para o setor. Todas essas alterações provocaram reações e adaptaçóes no ambiente institucional da cadeia produtiva, interferindo diretamente no contexto comercial, estrutural e organizacional do setor lácteo brasileiro.

Esse cenário de intensas e constantes mudanças torna-se propício para o surgimento de indagações, tais como: qual o comportamento geral da cadeia do leite no Brasil durante e após a implementação dessas alterações no seu ambiente institucional? E como reagem os agentes participantes dessa cadeia produtiva, especialmente aqueles responsáveis pela maior parte da produção? São questões de difícil elucidação e a abordagem para respondê-las envolve aspectos que perpassam o contexto histórico e as perspectivas da atividade leiteira no Brasil.

No caso da agricultura familiar, termo que designa uma variedade de atores que têm em comum a atividade agrícola e a utilização predominante do emprego de mão de obra familiar, a pecuária leiteira é historicamente uma atividade de grande relevância para a geração de emprego e renda. De acordo com Guilhoto et al. (2007), a atividade leiteira em 2006 gerou valor total em torno de $\mathrm{R} \$$ 6,7 bilhões, sendo que o segmento da agricultura familiar foi responsável por $59 \%$ de todo esse valor, enquanto que o segmento empresarial obteve $41 \%$. Uma vez em funcionamento, a atividade leiteira desencadeia um acúmulo gradual no patrimônio familiar mediante aplicação constante e diária de trabalho familiar para a ordenha, manutenção das instalações, tratamento e alimentação do rebanho. No entanto, os resultados positivos desta atividade oscilam de acordo com o tipo de animal criado, a forma de alimentação do rebanho, a quantidade de animais por área, o montante de investimentos, entre outros fatores. Portanto, existe uma diversidade significativa de sistemas de produção leiteira no Brasil (NORDER, 2006).

Dada essa importância para a agricultura familiar, um novo fator legal dentro da cadeia produtiva do leite tende a levantar preocupações quanto a possíveis limitações à manutenção da atividade nessa categoria de produtores. Um evento importante nesse sentido ocorrido recentemente foi o arcabouço legal instituído através da Instrução Normativa n. 51 (IN51), de 18/09/2002. A IN51 está inserida no contexto das políticas públicas de regulação da produção e circulação de produtos agropecuários no Brasil. Nesse sentido, de acordo com a abordagem clássica de Lowi (1964), apud Souza (2007), a IN51 se enquadra como uma política pública regulatória, envolvendo burocracia e grupos de interesse, na medida em que ela configura-se como uma intervenção formal, ancorada no poder de coerção do Estado, em um ambiente institucional específico.

O presente estudo busca identificar quais são as percepções e as decisões tomadas 
pelos agricultores familiares da região Oeste de Santa Catarina a partir da necessidade de buscar conformidade às exigências dessa nova normativa, e se essa condição tem sido determinante para as decisões de investimento na produção a médio e longo prazo. Trata-se de investigar a incidência territorial de uma política pública (SILVA, 2008, 2009), neste caso, a IN51. Parte-se da premissa de que essa normatização irá incidir territorialmente de fato nas localidades que se caracterizam como "bacias leiteiras", como ocorre no Oeste Catarinense.

A região oeste de Santa Catarina foi escolhida em virtude de sua importância produtiva para a bacia leiteira da região Sul e por suas características agropecuárias e fundiárias, baseadas em pequenas unidades familiares. Essa região conta com uma população de aproximadamente 1,3 milhões de habitantes em 111 municípios e, apesar da recente colonização, tem um dos maiores complexos agroindustriais de suínos e aves do Brasil (IBGE, 2006). Por isso, sua economia baseia-se na agropecuária, atividade responsável por dois terços do movimento econômico dos municípios.

Embora o Oeste Catarinense não apresente características morfológicas tão promissoras relacionadas aos recursos naturais, seu território tem uma concentração de grandes empresas agroindustriais convivendo com uma estrutura social baseada num expressivo segmento de agricultores familiares. Isso faz com que a região apresente uma dinâmica econômica razoável mas, por outro lado, convive com indicadores de exclusão e de desigualdades sociais não tão louváveis, além de sofrer com vários problemas ambientais relativos a solos e águas (FAVARETO, 2006).

Nesse sentido, este texto está organizado em seis partes, além da introdução. No tópico dois, são apresentados brevemente os procedimentos metodológicos utilizados para a aferição dos resultados procurados. No tópico três, são descritas as caracterizações gerais que circundam a cadeia produtiva leiteira no Brasil e como a agricultura familiar se insere. $\mathrm{O}$ tópico quatro traz uma descrição dos principais preceitos da Nova Economia Institucional (NEI) como instrumental analítico na investigação de cadeias produtivas. O tópico cinco apresenta os aspectos gerais do ambiente institucional da cadeia produtiva leiteira no Brasil. No tópico seis, encontram-se os principais resultados quanto às análises efetuadas sobre a incidência territorial dessa mudança institucional no Oeste Catarinense. Por último, são tecidas algumas considerações conclusivas sobre o trabalho.

\section{Procedimentos metodológicos}

A realização deste trabalho foi definida como sendo um estudo de caso $^{3}$. Instrumentos de mensuração quali-quantitativa foram utilizados, concentrando-se na investigação das principais influências do ambiente institucional, após a implementação de legislação específica para a cadeia leiteira no Brasil, sobre um grupo de agricultores familiares ligados a uma cooperativa de laticínios no Oeste Catarinense, com base no instrumental teórico da Nova Economia Institucional (NEI).

Foram realizadas duas coletas de informações que serviram para estabelecer os principais aspectos relacionados às interferências do ambiente institucional na agricultura familiar, a partir da introdução de uma legislação específica, a IN51, que determina novas formas de produção, análise de qualidade, armazenamento, transporte e classificação do leite, verificando a existência de possíveis impactos para a economia familiar.

A primeira análise foi realizada por meio de entrevistas semiestruturadas com questionamentos abertos, que foram respondidas por pessoas consideradas informantes qualificados para a cadeia produtiva do leite na região estudada. Fizeram parte do grupo de informantes

3 Em geral, os estudos de caso representam uma estratégia recomendada quando o pesquisador tem pouco controle sobre os acontecimentos e quando o foco se encontra em fenômenos sociais complexos da vida real. Para mais detalhes sobre as características de um estudo de caso, ver Yin (2005). 
qualificados desta pesquisa nove pessoas, que direta e indiretamente têm relação com a cadeia produtiva do leite e agricultura familiar na região pesquisada, entre eles: técnicos extensionistas, empresários, gestores públicos e representantes sindicais. A identificação e a escolha dessas pessoas foram definidas pelas suas qualificações profissionais, representatividade dentro do setor, ou pelo seu envolvimento com os agricultores familiares produtores de leite da região.

O segundo levantamento foi efetuado por meio da aplicação direta de questionários fechados, em uma amostra de agricultores familiares ligados a uma cooperativa regional de produção de leite. Ao todo, foram entrevistados 58 agricultores familiares, conforme enquadramento no Programa Nacional de Fortalecimento da Agricultura Familiar (Pronaf), com diferentes níveis de produção, tempo de associação na cooperativa e municípios. Nessa segunda parte, o objetivo foi verificar a coerência existente entre os informantes e a realidade da amostra pesquisada.

As principais informações obtidas nos dois estágios de pesquisa de campo foram cruzadas e tabuladas graficamente com vistas a entender quais as percepções e estratégias dos atores sociais envolvidos na cadeia produtiva leiteira da região diante das alterações no ambiente institucional com a introdução da IN51.

\section{A cadeia produtiva leiteira e a agricultura familiar}

Nos últimos anos, especialmente nas duas últimas décadas, o leite passou a ser consumido em quantidades maiores em todo o mundo. Essa expansão do consumo de leite estimulou o surgimento de novas técnicas de produção, armazenagem e transporte, provocando diretamente a elevação da produção e produtividade em níveis mundiais e o surgimento de condições para aumentar o prazo de utilização e estocagem do produto, como foi o caso das embalagens cartonadas tipo "Longa Vida" (OLIVEIRA, 2008).
Segundo dados da Embrapa Gado de Leite ${ }^{4}$, a produção nacional supera os 25 bilhões de litros leite por ano. Todavia, menos da metade dessa produção passa por algum serviço de inspeção sanitária, o que é uma das maiores dificuldades para o atendimento das expectativas de qualidade impostas pelo ambiente institucional que norteia a produção, a armazenagem, o transporte e a industrialização do leite no País. Outro ponto importante é que o perfil produtivo de leite, sobretudo nos estados do Sul do País, é de pequenas e médias produções, em torno de 100 litros/dia por propriedade (EMBRAPA, 2010).

Como reflexo dessa expansão de consumo, somente no caso do leite bovino, entre 1996 e 2006, ampliou-se a produção mundial em 18\%, passando de 467 bilhões para 550 bilhões de litros. Esse aumento se deu em decorrência da tentativa de responder ao rápido e contínuo crescimento da demanda pelo produto. A elevação do consumo em termos mundiais está baseada em alguns fatores, tais como: a maior abertura comercial ocorrida nesse período, que favoreceu a redução de barreiras de comercialização entre os países; o aumento de consumo per capita em vários países; o próprio aumento populacional mundial; e o ingresso de novos hábitos alimentares à base de derivados de leite, sobretudo em locais onde a cultura alimentar não se baseava nesse produto, como é o caso do continente asiático, que entre os anos 2000 e 2006 aumentou seu consumo de 90,5 para $131,4 \mathrm{~kg} /$ pessoa/ano (EMBRAPA, 2010).

Decorrente deste maior fluxo comercial entre países consumidores e produtores de leite, a exploração comercial dessa atividade vem conquistando cada vez mais novos adeptos, tornando-se um importante produto no agronegócio mundial. No entanto, as mesmas demandas que impulsionam a produção e produtividade no setor, também impulsionam novos (ou acentuam velhos) problemas na cadeia produtiva leiteira. Nessa esfera de intenso dinamismo nas relações de mercado

\footnotetext{
4 Mais informações sobre a produção de leite no Brasil podem ser consultadas no site: www.cnpgl.embrapa.br
} 
entre produtores, fornecedores, indústrias, varejistas e consumidores de leite, alguns agentes da cadeia aproveitam-se de lacunas operacionais e legais para realizarem operações fora do convencional, com vistas à conquista de vantagens competitivas de forma oportunista. Esse comportamento acontece principalmente porque as condições legais e éticas têm brechas e não são bem resolvidas e respeitadas, criando um círculo vicioso de desconfiança mútua entre os participantes da cadeia.

Em meio ao ambiente competitivo do mercado do leite, algumas situações surgem e trazem descrédito para toda a cadeia produtiva ${ }^{5}$, demonstrando ineficiências no aparato legal, a incapacidade de fiscalização e controle de qualidade dos produtos lácteos por parte dos governos e as brechas para práticas de comportamentos oportunistas. Essa realidade contribuiu ainda mais para estabelecer um ambiente de intensas desconfianças em relação à qualidade e ao controle sanitário, atingindo principalmente os consumidores de leite.

Esse mercado volátil e vulnerável do leite é constituído de várias formas híbridas de governança, sendo praticamente impossível estabelecer uma forma única de coordenação da cadeia via mercado ou integração total (vertical), pois as próprias características produtivas no Brasil impedem tal organização. Com isso, alguns segmentos importantes da produção de leite, como a agricultura familiar, passam a ter mais dificuldades em se inserirem nesse contexto competitivo da cadeia produtiva do leite, devido a uma série de fatores socioeconômicos, ficando dependente das ações de outros agentes, como agroindústrias e transportadores, para permanecerem atuando no setor. Por outro lado,

5 Em outubro de 2007, a credibilidade na cadeia produtiva leiteira no Brasil teve novos golpes, quando foi descoberta, no estado de Minas Gerais, a realização de processos para a alteração dolosa da composição do leite, inclusive com adição de substâncias prejudiciais à saúde humana, entre elas o peróxido de hidrogênio (água oxigenada). Essas estratégias tinham como objetivo aumentar a quantidade do produto e o período de validade, permitindo maior tempo de acondicionamento sem o risco de deterioração do produto nas prateleiras (OLIVEIRA, 2008). a produção de leite na agricultura familiar pode representar a soberania e a segurança alimentar da família, visto que, além de fornecer o produto para o consumo próprio, essa atividade garante ingresso mensal de renda monetária. Isso significa que por meio da atividade leiteira o agricultor familiar pode manter as despesas mensais, normais a qualquer família, e constituir um fundo de capital de giro capaz de contribuir decisivamente para a viabilização de outras culturas perenes ou sazonais.

Embora a pecuária leiteira garanta à unidade familiar um fluxo de renda mensal e estável, ela também demanda uma intensa absorção da força de trabalho, seja na ordenha, na manutenção das instalações, ou no tratamento e alimentação do rebanho. Devido a essa constatação, parte das famílias, especialmente as mais numerosas, depara-se com a necessidade não só de aperfeiçoar continuamente o sistema de criação, mas também de buscar uma intensificação e diversificação do uso do solo com a finalidade de aumentar a geração de renda e, concomitantemente, encontrar formas de ocupação produtiva para os filhos. Por isso, muitas famílias desenvolvem a pecuária junto a outros plantios e criações (fruticultura, horticultura, suinocultura etc.) e, com isso, diversificam as formas de uso do solo, dos recursos produtivos e da força de trabalho (NORDER, 2006).

Em relação ao Oeste Catarinense, Oliveira (2008) pontua que a região possui um dos maiores percentuais de contingente rural do estado de Santa Catarina, com 37\% de sua população residindo em áreas rurais. Tal fator é decisivo para que a região se constitua em uma das principais bacias leiteiras do estado. O Oeste Catarinense produz aproximadamente 1,5 milhão de litros de leite diariamente, sendo que $95 \%$ desta produção total vem de regimes produtivos considerados de base familiar (OLIVEIRA, 2008).

De acordo com Testa (2003), a bacia leiteira do Oeste Catarinense tem evoluído a tal ponto que o leite já é o maior responsável pela capacidade de geração e agregação de valor nas propriedades e descentralização de unidades industriais. Além disso, é uma atividade que tem grande 
alcance social e permite o uso de terras consideradas pouco aproveitáveis para outras culturas e capilaridade para a absorção de mão de obra familiar. Destaca-se, nesse sentido, a capacidade de ocupação e manutenção de mão de obra no meio rural, inclusive em períodos de sazonalidade nas culturas perenes ou anuais.

Conforme Mello e Ferrari (2003), os aspectos anteriormente expostos, aliados a vantagens do ingresso mensal de receitas para família, à dinâmica de distribuição de renda para o comércio local e ao recolhimento de impostos diretos e retornos indiretos, têm rendido ao leite o status de atividade âncora na maioria das propriedades familiares do Oeste Catarinense. Os autores apontaram também que a produção de leite, especialmente no Oeste Catarinense, se constitui na última alternativa com capacidade de abranger e envolver um grande contingente de agricultores familiares. Essa constatação se deve ao fato de que essa atividade já está presente entre os agricultores familiares da região que, portanto, não se constitui em uma dificuldade ou barreira à entrada (diferente da suinocultura e aves), possibilitando a expansão gradativa e planejada conforme a capacidade de trabalho e a disponibilidade de terra e capital para investimentos da família.

\section{O ambiente institucional na nova economia institucional}

A Nova Economia Institucional (NEI) estimulou o surgimento de um novo paradigma econômico baseado no estudo mais sistêmico das firmas e seus ambientes, ultrapassando as antigas retóricas da busca desenfreada pela eficiência da produção com custos/insumos mais baixos, trazendo diferenças significativas na análise das firmas em relação ao velho institucionalismo. Dentre as principais diferenças propostas pela NEI está a valorização das instituições e o estudo do modo como estas interferem no ambiente competitivo, provocando reflexos no desempenho econômico das firmas. O ambiente institucional é apresentado pela NEI como parte integrante da teoria de Custos de Transação, pois ele pode ser responsável pelo surgimento, eliminação, redução ou ampliação dos custos de transações (ZILBERSZTAJN, 1995; CLARO, 1998; ALSTON, 1999).

O estudo do ambiente institucional baseia-se na compreensão das mudanças (ou não) ocorridas por força das instituições e seus reflexos para as demais instituições e firmas de uma determinada cadeia ou setor. Segundo North (1991), as instituições são limites que a sociedade se impõe para estruturar as relações políticas, econômicas e sociais que interferem nas transações entre os agentes, podendo ser classificadas em dois tipos: formais e informais. $\mathrm{O}$ autor atribui às instituições formais $\mathrm{O}$ conjunto de leis, regulamentos, contratos escritos, entre outras formas pré-definidas, compondo o sistema normativo que deve reger, ou pelo menos indicar, um determinado comportamento esperado ou pretendido entre os agentes. Aspectos legais estão diretamente ligados às intervenções governamentais que geralmente afetam as estruturas produtivas e os comportamentos das cadeias e indústrias. Já as instituições informais também compõem uma força coercitiva sobre a sociedade; contudo, essas forças não são visíveis, nem tampouco contratualizadas. Normalmente são formadas pelo conjunto de tradições, costumes e ritos da sociedade. A religião pode ser citada como um exemplo importante de instituição informal que exerce pressão sobre os imperativos para comportamentos aceitáveis coletivamente (BARCELOS, 2003).

Para Figueira e Belik (1999), o ambiente institucional tratado pela NEI é dado pelo conjunto de regras sociais, legais e políticas que estabelecem as bases para a produção, troca e distribuição, criando um sistema de intervenção externa em que a firma

\footnotetext{
6 Para a Nova Economia Institucional (NEI), custos de transação referem-se à parcela do valor de uma negociação ou transação de valores econômicos que é apropriada por agentes diferentes daqueles que estão negociando, ou seja, é o valor apropriado por terceiros. Os custos de transação são, portanto aqueles com os quais os agentes se defrontam toda vez que necessitam recorrer ao mercado, e estes custos seriam, do modo mais formal, os custos de negociar, redigir e garantir que um contrato será cumprido (WILLIAMSON, 1989).
} 
Figura 1. Estrutura do ambiente institucional e organizacional das cadeias produtivas.

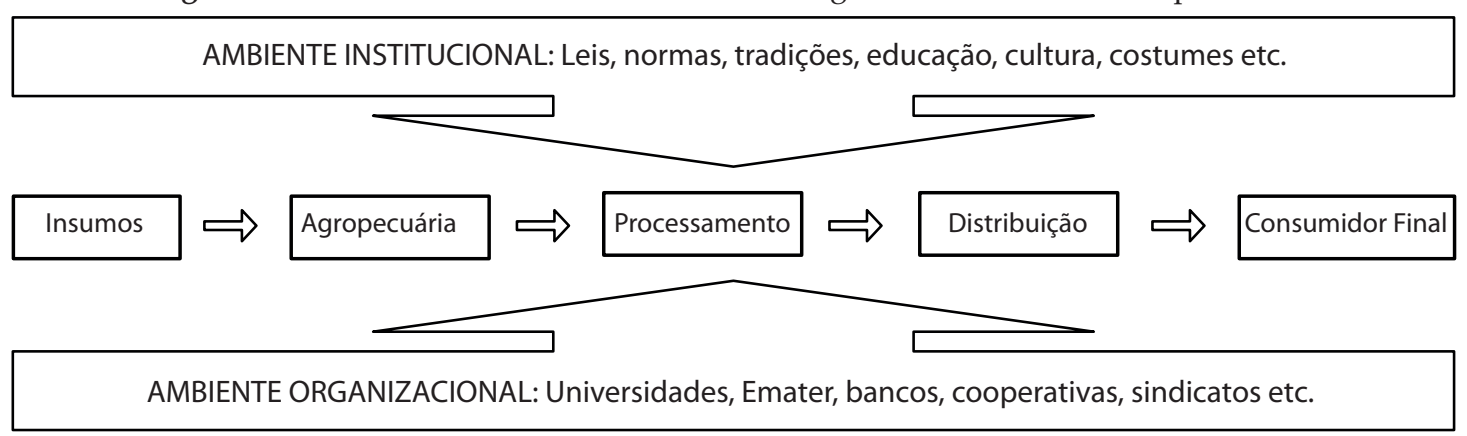

Fonte: Adaptado de Zylbersztajn (2000).

"obriga-se" a obedecer e reproduzir. Isso pode gerar ou reduzir custos. Quando há alterações bruscas nesse ambiente pelas novas regras institucionais impostas, abrem-se novas oportunidades e ameaças para os agentes integrantes do sistema produtivo em questão.

Na NEI, ambas as formas de instituições devem ser consideradas, pois interferem diretamente na conduta e estratégias escolhidas pelas firmas. Instituições informais influenciam instituições formais e vice-versa. Porém, existem diferenças entre o tempo e a forma de atuação das instituições formais e informais. Enquanto as instituições formais passam por mudanças de curto e médio prazo, necessitam do braço coercitivo e fiscalizador do Estado para coexistirem e são constituídas após um desejo coletivo expressado de forma explícita, as instituições informais não necessitam da ação do Estado. Muito pelo contrário, por vezes são as responsáveis pela redução e eliminação dessa força. Esse tipo de instituição normalmente não muda com muita frequência, necessitando de um longo prazo para se consolidarem, serem reproduzidas e interferirem no contexto coletivo (WILLIAMSON, 2000).

Conforme North (1991), uma mudança no ambiente institucional adquire importância quando é internalizada pelos agentes, ou seja, os participantes de uma determinada cadeia percebem e reconhecem essa força como uma mobilizadora e indutora de mudanças internas. Dessa forma, a mudança no ambiente institucional, baseada no aspecto normativo (leis, regras ou decretos), somente se efetiva quando for reconhecida, aceita e replicada pela maioria dos agentes, gerando, assim, diferentes reações para adaptação das organizações frente a essa nova realidade institucional.

O ambiente organizacional também é muito importante para a definição da estrutura de uma cadeia produtiva. O ambiente organizacional é formado pelo conjunto de organizações que são criadas para dar suporte a um determinado Sistema Agroindustrial (SAG) ${ }^{7}$. Essas organizações buscam determinar como o SAG deve funcionar. Elas podem ser universidades, sindicatos, conselhos, cooperativas, associações de produtores, entre outros. Em geral, as organizações nascem para defender interesses, provocar mudanças institucionais, reclamar o surgimento de novas políticas públicas. Um detalhe importante é que as organizações mudam com certa rapidez, enquanto que as instituições mudam com mais dificuldades. As empresas até se adaptam ao ambiente institucional, mas fazem pressões para que as regras sejam mais adequadas aos seus interesses (ZILBERSZTAJN, 2000). A Figura 1 a seguir apresenta esquematicamente como o ambiente institucional é organizado ou modelado a partir da combinação de forças exercidas pelos seus componentes.

\footnotetext{
7 Sistema Agroindustrial (SAG) é definido como "um conjunto de relações contratuais entre as empresas e agentes especializados, cujo objetivo final é disputar o consumidor de determinado produto" (ZYLBERSZTAJN, 2000, p. 13).
} 


\section{O ambiente institucional da cadeia leiteira no Brasil}

Como dito anteriormente, o ambiente institucional da cadeia produtiva do leite passou por várias modificações a partir dos anos 1990. Dentre as principais causas estão: a abertura comercial nos anos 1990, a desregulamentação dos preços do leite na mesma década, a influência do ingresso de leite importado dos países do Mercosul, o gradual aumento no consumo interno, a valorização internacional da produção a base de pasto (principalmente após o episódio da "vaca louca" na Europa Ocidental), as políticas governamentais (ou a falta delas), o desmantelamento de pequenas unidades e cooperativas beneficiadoras de leite em regiões de acesso precário, entre outros motivos. Esses aspectos facilitaram o ingresso de grandes grupos lácteos, nacionais e internacionais, que direta e indiretamente tentaram reorganizar a agroindústria e a cadeia produtiva do leite (BREDA, 2000).

Por outro lado, essas condições vieram acompanhadas de novas possibilidades para o setor. Entre elas podem-se citar: a estabilização da economia brasileira, a ampliação da capacidade de compra dos consumidores, maior diversificação do mercado de produtos lácteos e, principalmente, os investimentos em pesquisa e desenvolvimento na elaboração de produtos com maior vida útil, tornando-o mais adequado e prático para comercialização, como foi o caso do leite longa vida.

Outro aspecto do ambiente institucional que envolve a cadeia do leite no Brasil está relacionado com as exigências dos consumidores quanto à qualidade e à capacidade de os produtos lácteos satisfazerem as necessidades nutricionais, processos sustentáveis de produção e segurança alimentar. Segundo Breda (2000), essas exigências têm criado um ambiente de estímulo às ações cooperativas e coordenadas entre os diferentes segmentos que compõem a cadeia produtiva do leite, especialmente entre o produtor e a indústria, que vêm traçando metas comuns para atender essas novas demandas institucionais.
Um dos problemas que persiste na cadeia produtiva do leite no Brasil é a assimetria de informações entre os agentes. Esse fator possibilita o surgimento de comportamentos oportunistas e incertezas tanto para o produtor quanto para a indústria. Por um lado, o agricultor desinformado acerca das novas exigências de qualidade (impostas institucionalmente) e que não são bem compreendidas por ele ${ }^{8}$; por outro, a indústria que tenta reduzir custos de monitoramento de qualidade somente na hora da coleta da matéria-prima e que geralmente estipula remuneração por quantidade e não por qualidade? .

Entretanto, alguns autores alegam que as mudanças são impulsionadas pelas exigências dos consumidores e que são as indústrias as principais responsáveis pelo compromisso de estabelecer essa nova ordem para os demais elos da cadeia. Para Dürr (2004), sempre que a agroindústria processa mudanças em seus processos de produção, necessariamente, as empresas rurais se adaptam e se reestruturam internamente para continuar fornecendo o tipo de matéria-prima que o mercado exige. Para ele, tem sido assim com as cadeias produtivas das aves e dos suínos e provavelmente será o destino no caso do leite.

$\mathrm{Na}$ cadeia produtiva do leite, o Estado tem contribuído significativamente para a modificação do ambiente institucional nos últimos anos. Em 1989, por exemplo, foi instituída a Lei Federal n. 7.889/89, que atribuiu às Unidades Federativas a competência para inspeção e fiscalização sanitária e industrial dos produtos de origem animal, sendo uma alteração que já começava a atingir as indústrias de lacticínios (OLIVEIRA, 2008). Dois anos mais tarde, em 26 de março de 1991, aconteceu a assinatura do Tratado de Assunção, que formalizou a constituição do Mercosul. A expectativa era que

8 Esse problema é fruto especialmente da desarticulação do serviço público de assistência técnica e extensão rural no Brasil.

9 Um fator de utilização frequente por parte da indústria é o recolhimento sem preço, em que o agricultor somente saberá a remuneração da sua produção 15 ou 30 dias após a entrega. 
medidas como o livre mercado de bens, serviços e fatores de produção, harmonização das políticas aduaneiras, posicionamento em bloco frente a países não membros e o ajustamento das políticas econômicas influenciassem significativamente a produção e a comercialização de leite no Brasil, principalmente porque a Argentina e o Uruguai estavam mais consolidados no setor lácteo, com maior produtividade e qualidade, o que deveria elevar indiretamente a produção e qualidade dos demais países produtores de leite participantes do bloco.

Em 1997, com a necessidade de se estabelecer critérios mínimos de qualidade para o produto leite, foi criado o Plano Nacional de Qualidade do Leite (PNMQL), por iniciativa do Ministério da Agricultura e com participação direta de órgãos de ensino e pesquisa, entidades representativas das indústrias e dos produtores. Conforme afirmou Dürr (2004), a criação do PNMQL foi considerada o momento mais importante para a organização da cadeia leiteira nos últimos anos, ao constituir-se na melhor oportunidade para que a produção de leite do País seja respeitada em outros países, aproximando os patamares de qualidade àqueles mundialmente aceitáveis.

O fato mais concreto dos vários momentos do PNMQL foi a constituição e publicação da Instrução Normativa 51, em $2002^{10}$. A IN51 foi instituída para definir regulamentos técnicos e operacionais para a produção, identidade, classificação e qualidade dos diversos tipos de leite existentes, bem como determinar as condições para o seu resfriamento, armazenagem e transporte. Essa normativa estava prevista para

10 Essa legislação foi precedida pela Portaria Ministerial n. 56 que tinha sido publicada pela Secretaria da Defesa Agropecuária e de Abastecimento no Diário Oficial da União n. 234, em 8 de dezembro de 1999. A IN51 foi editada em setembro de 2002 pelo Ministério da Agricultura Pecuária e Abastecimento (Mapa) porque uma Portaria não permitiria a realização de alterações substanciais na legislação, principalmente em um regulamento, como era o caso do Riispoa (1952). Embora a IN51 tenha sido publicada em 2002, somente em julho de 2007 ela entra em vigor em todo o território nacional. entrar em vigor em julho de $2002^{11}$. Contudo, devido ao ambiente organizacional pouco favorável, com existência de fortes resistências, foi exigida a prorrogação dos prazos de início de cobrança por duas vezes. As entidades representativas dos pequenos produtores formavam o principal bloco organizacional de resistência ao texto original.

As principais exigências da IN51 são: necessidade de refrigeração do leite cru na propriedade; coleta de leite a granel; adoção de novos critérios de qualidade para o leite cru comercializado no País, baseado na Contagem de Células Somáticas (CCS); Contagem Padrão em Placas (CPP); controle de resíduos; teor mínimo de proteínas e controle de temperatura. Tais questões exigem das unidades produtoras a necessidade de novos investimentos para o resfriamento e a realização de exames de análise mais detalhada. A IN51 trouxe como grande novidade para o setor a criação da denominação de "leite cru resfriado", referindo-se à matéria-prima, na forma fluida, recebida pela indústria de transformação, que gradativamente deverá induzir a substituição e eliminação do leite tipo C e posteriormente tipo $B$, passando a ficar somente um tipo de leite, o tipo A.

De acordo com Breda (2000), essa normativa talvez represente a maior mudança institucional já ocorrida em uma cadeia agroalimentar brasileira. Ela estimula indiretamente o melhoramento genético e produtivo dos rebanhos. Dessa forma, essa legislação incide diretamente na seleção, por qualidade e por competitividade, dos produtores. Ela determinou a realização de análises laboratoriais de qualidade de leite em cada propriedade, identificando problemas na origem, ao contrário do que vinha sendo realizado, quando a qualidade do produto somente era inspecionada no recebimento pela indústria, com leite de boa e má qualidade misturado e homogeneizado nos tanques, sem os devidos controles nas coletas.

\footnotetext{
11 As novas normas entraram em vigor em julho/2005 para os estados do Sul e Sudeste. Para os demais estados, o cumprimento das normas está sendo exigido desde julho de 2007.
} 
Todavia, segundo Dürr (2004), é possível asseverar que a falta de controle de qualidade mais específica para o leite gera problemas para toda a sua cadeia, tais como: perdas econômicas com o descarte de leite; riscos para o consumidor; falta de uniformidade nos critérios de inspeção e baixa competitividade do Brasil como mercado exportador. O mesmo autor faz uma ressalva ponderando que a entrada em vigor da IN51 não garante por si só a qualidade do produto, pois ela não é atribuída simplesmente por decretos, e os principais desafios para a melhoria do leite passam pelos seguintes aspectos:

a) Melhorias na infraestrutura do meio rural;

b) Definição de objetivos comuns a todos os elos da cadeia produtiva do leite, em torno da qualidade do produto;

c) Campanhas junto aos consumidores sobre perigos de consumo de leite não inspecionado, ou comercializado informalmente;

d) Definição de processos e sistemas de remuneração da matéria-prima pela qualidade;

e) Implantação de um cadastro de produtores e rebanho, permitindo a formação de um banco de dados e rastreabilidade;

f) Monitoramento da qualidade do leite segundo os critérios dos novos regulamentos;

g) Criação de um amplo programa de educação para a qualidade, que atinja todos os níveis da cadeia do leite.

A pequena escala e a forma atomizada de produção da maioria dos produtores, que impedem investimentos necessários em tecnologias, são alguns dos graves problemas apontados por Dürr (2004) que dificultam ou limitam a estruturação da cadeia. Para resolver o problema da baixa escala de produção dos agricultores familiares, o autor recomenda uma intervenção mais incisiva voltada para a profissionalização de produtores de leite de pequeno porte. Dürr (2004) alegou que há necessidade de mudanças na matriz de produção de leite, com impactos econômicos e sociais previamente mensurados e entendidos.
Profissionais de pesquisa e assistência técnica têm a obrigação ética de buscar meios de esse produtor tornar-se um profissional na atividade leiteira a tal ponto que atinja uma escala de produção que lhe permita uma renda digna e capital para investir na infra-estrutura necessária à produção de um leite de alta qualidade, deixando de ser massa de manobra de alguns políticos "comprometidos" com a agricultura familiar. [...] Nesse horizonte entram a contribuição da pesquisa e da extensão, a profissionalização das entidades que representam os interesses comerciais dos produtores, o associativismo e a especialização das atividades de produção de leite (DURR, 2004, p. 48-49).

Para Dürr (2004), a questão que se impõe onde a produção de leite é essencialmente oriunda de pequenas empresas rurais é: devemos simplesmente rejeitar a legislação que exclui aqueles produtores incapazes de atingir os padrões mínimos estabelecidos ou devemos propor alternativas que permitam a permanência na atividade do maior número de rebanhos possível, mas que ao mesmo tempo promova a melhoria da qualidade do leite oferecido ao consumidor?

\section{As consequências no novo ambiente institucional para a agricultura familiar na cadeia leiteira no Oeste Catarinense}

Neste tópico são apresentados os principais resultados das análises das entrevistas e da literatura consultada para entender as consequências da IN51 e sua incidência territorial no Oeste Catarinense.

Conforme afirmado por todos os informantes qualificados abordados nesta pesquisa, a IN51 é considerada uma importante mudança no ambiente institucional da cadeia produtiva do leite na região, que tende a provocar impactos 
de ordem econômica, produtiva e social em médio e longo prazos. A divergência está sobre o caráter desse impacto. Enquanto uns associam essas mudanças com oportunidade de negócio, aumento e profissionalização da produção, outros a consideram uma ameaça para a produção e, consequentemente, para a economia da agricultura familiar da região. Outros comentários revelam que a IN51 tem produzido diferentes leituras sobre as alterações na cadeia produtiva do leite. Essas leituras, ao mesmo tempo em que confirmam o reconhecimento e amparo institucional da IN51, trazem à tona a diferença de velocidade de aceitação dessa normativa. Isso acontece em virtude da avaliação que cada agente faz em relação aos benefícios ou prejuízos que tais mudanças venham causar às unidades produtivas.

Um ponto que gerou fortes divergências é o que diz respeito à intensidade de aplicação da IN51 sobre a agricultura familiar da região. Por meio das falas dos entrevistados, é possível perceber que há discordância quanto à aceitação integral das regras contidas na IN51. Esse aspecto contribui para acirrar a discussão sobre o ambiente em torno da efetividade da IN51, reduzindo sua força e seu enraizamento institucional.

Ainda sobre o reconhecimento, nem todos os entrevistados admitem que as mudanças provocadas pela IN51 podem ser consideradas como benéficas para a agricultura familiar, como revela o depoimento abaixo:

O problema da criação desta lei foi que ela não considerou a realidade produtiva de todo o Brasil. Aqui no Sul, a maioria dos produtores é formada por pequenos, que têm essa atividade como uma geradora de renda importante para sua família, mas sem condições de realização de investimentos pesados. Vai ter exclusão sim na agricultura familiar, e ai, o que o Estado deverá fazer com essa turma? Mandar para as cidades? Ou pagar bolsas família? (Extensionista de entidade privada)
Dois outros fatores foram lembrados pelos entrevistados como dificuldades à efetivação imediata da IN51. Segundo eles, a estrutura produtiva da região, formada por inúmeros produtores (atomizada), e o provável assédio por matéria-prima das empresas recém-instaladas nas regiões norte do Rio Grande do Sul e oeste de Santa Catarina são fatores que dificultam a imediata cobrança dos patamares de qualidade baseada na IN51. A outra se refere à capacidade de intervenção das forças representativas da agricultura familiar. No entendimento dos entrevistados, essas organizações provocaram mudanças significativas no texto inicial proposto para gerar esse arcabouço. Por essa razão, essas intervenções no ambiente institucional provocaram mudanças que tornaram as regras da IN51 menos severas para a agricultura familiar, modelando-se parcialmente às necessidades desse grupo. Dessa forma, apoiado pelas opiniões dos entrevistados, pode-se afirmar que a IN51 é considerada uma significativa alteração no ambiente institucional da cadeia produtiva do leite.

$\mathrm{Na}$ interpretação dos entrevistados, os maiores beneficiados com essas mudanças institucionais seriam os consumidores, as indústrias e os lacticínios, os "bons" produtores, as prefeituras e os estados, por meio da arrecadação de impostos. Todos esses agentes estão mais a jusante na cadeia produtiva do leite. Entretanto, algumas opiniões levaram a crer que o processo de cobrança efetiva da IN51 poderia acarretar prejuízos ou danos na participação de alguns agentes da cadeia. Essas situações seriam mais visíveis nos produtores de pequena escala e com baixa ou nenhuma capacidade de investimento imediato.

Para verificar os pontos de estrangulamento para a atividade leiteira na agricultura familiar e fazer uma correlação com as mudanças institucionais provocadas pela IN51, acrescentou-se uma questão em que os entrevistados indicaram o principal fator limitante para a expansão da produção de leite em suas propriedades. 
Figura 2. Limites para a expansão da atividade segundo entrevistados.

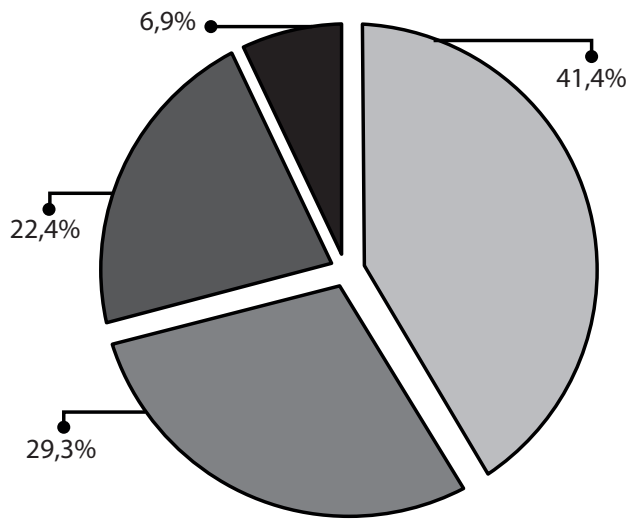

Fonte: Dados de entrevistas com agricultores, elaboração dos autores.

Por meio da Figura 2, percebe-se que a mão de obra é o principal limitante para a ampliação da atividade. Esse dado permite a construção de duas hipóteses: as unidades familiares estão com sua capacidade de trabalho bem aproveitado nas atuais atividades produtivas e com isso teriam impedimentos para a intensificação em alguma outra atividade específica, ou elas passam por dificuldades em manter seus postos de trabalho em virtude da dificuldade na sucessão familiar e pelo acelerado êxodo juvenil. Ambas as situações comprometeriam a expansão da atividade leiteira em curto prazo. Nesse ponto, o agricultor teria a opção de contratar permanentemente maior volume de serviços de terceiros, mas isso acarretaria desenquadramento da propriedade para políticas públicas da agricultura familiar. O êxodo das pessoas mais jovens é um dos fatores que impedem a transmissão da gestão e continuação das operações tradicionais na propriedade familiar. $\mathrm{O}$ envelhecimento da população, o desgaste emocional, a aposentadoria e o surgimento de doenças laborais são situações que provavelmente dificultarão a realização de fortes investimentos nas atividades produtivas da unidade familiar na região.

O fator insuficiência de espaço/terra, que teve percentual de quase $30 \%$, também pode se constituir em limite para a agricultura familiar. É limite não só para a atividade leiteira, mas também para as demais atividades que exigem maior alocação de terra. Dos entrevistados, $22 \%$ afirmam que o principal empecilho para a ampliação da atividade do leite passa pela falta de capital para novos investimentos. Nesse aspecto, fica visível a falta de capitalização ou recapitalização oriunda da própria atividade leiteira. Por fim, como respostas ao item "outros fatores", foram levantadas considerações como o preço de produto e insumos, desconfiança no setor, falta de proteção para a atividade e políticas ambientais, representando 6,9\% das respostas.

Para analisar as reações frente às mudanças no ambiente institucional, pediu-se aos entrevistados que indicassem qual ação da IN51 eles consideram como a mais adequada para a adaptação da agricultura familiar ao processo de mudanças no setor lácteo.

Como é possível observar na Figura 3, a maior parcela dos entrevistados $(36,2 \%)$ acredita que a organização e operação de cooperativas de leite seja a melhor estratégia para a adequação da agricultura familiar às exigências da IN51, permitindo continuar a produção leiteira em suas propriedades. Constatou-se também que atualmente os agricultores familiares não percebem, não têm ou não acessam políticas públicas ligadas ao setor leiteiro, o que explica o segundo maior percentual das respostas, $32,8 \%$, para a exigência de políticas públicas. Para $15,5 \%$ dos entrevistados, a agricultura familiar somente permanecerá produzindo leite se houver 
Figura 3. Posição dos entrevistados quanto à melhor alternativa para adaptação da produção às exigências da IN51.

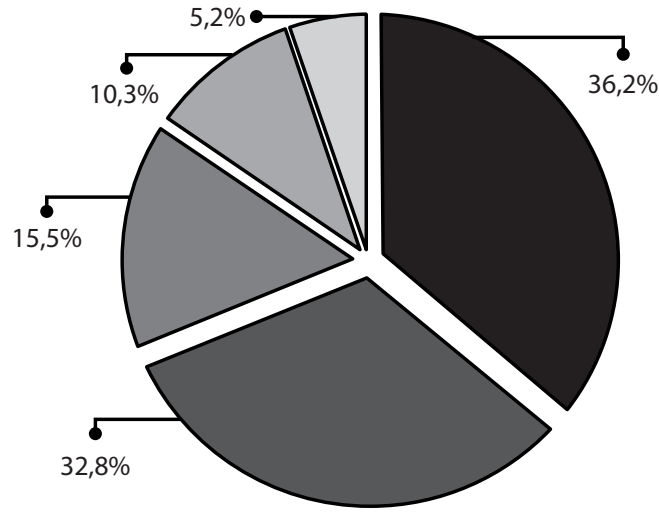

Fonte: Dados de entrevistas com agricultores, elaboração dos autores.
Organizador cooperativas

$\square$ Exigir políticas públicas

$\square$ Criação de outra Lei

$\square$ Buscar orientação técnica

$\square$ Priorizar a atividade leiteira alterações e/ou inclusão de novas legislações que considerem as características da produção familiar, como mostra o percentual de agricultores que refutam ou rejeitam a IN51, indicando a falta de relação entre essa legislação e suas realidades. Os 15,5\% restantes dividiram-se entre a busca por orientação técnica e priorização da atividade na família, indicando o percentual que afirma que somente através da especialização o agricultor produzirá leite com as condições exigidas.

Com relação ao papel do serviço de assistência técnica e extensão rural (Ater), as falas dos informantes qualificados ressaltaram a importância de um papel mais efetivo dos técnicos no auxílio aos agricultores familiares nesse processo de readequação tecnológica. Em geral, eles apontaram três possibilidades de atuação: a) uma Ater mais produtivista/difusionista, que pudesse responder à altura das necessidades da cadeia produtiva, incentivando os produtores à reconversão da produção familiar para o atendimento integral das normas da IN51; b) um serviço de Ater como "colchão de amortecimento", operando para diminuir ou dissipar os impactos negativos destas medidas normativas sobre a agricultura familiar; ou c) uma Ater com postura menos interveniente na cadeia produtiva do leite, operando de maneira mais sistêmica com os produtores excluídos pelo mercado, ou os desinteressantes sob o ponto de vista de escala comercial, atuando de forma mais assistencialista e com foco mais sobre as consequências do que as causas.

Percebeu-se que a maior preocupação dos agricultores familiares está no sentido de que a centralização e verticalização da produção são possíveis consequências negativas dessa normativa. Para os entrevistados, esse é o fato que tende a trazer mais prejuízos para a produção e economia da agricultura familiar da região, pois a integração levará a uma seleção natural dos produtores por três aspectos: escala produtiva, capacidade de sucessão dentro da família e investimentos destinados à atividade.

Nesse sentido, além do serviço de Ater, outras políticas públicas podem ser buscadas para auxiliar esse processo. Entre elas pode-se citar: o Pronaf Crédito, que pode auxiliar as unidades familiares no financiamento (a crédito subsidiado) da atividade de sua propriedade; o Pronaf Infraestrutrua, que fornece recursos para investimentos de maiores vultos e que possam ser utilizados por diversos grupos familiares; as políticas de apoio à comercialização de produtos da agricultura familiar, como o Programa de Aquisição de Alimentos (PAA), e mais recentemente, o Programa Nacional de Alimentação Escolar (Pnae); além dos programas de apoio a cooperativas e agroindústrias familiares, ligados ao Ministério do Desenvolvimento Agrário (MDA).

Para os entrevistados, essas modificações no ambiente institucional do setor leiteiro produzirão 
novas formas de configuração nas relações entre os agentes baseados, especialmente nas integrações. E essas novas configurações vão limitar, prejudicar e reduzir o poder de intervenção da agricultura familiar sobre a cadeia produtiva. Ou seja, diminui a possibilidade de intervenção da agricultura familiar no ambiente institucional da cadeia produtiva do leite. E esse resultado tende a se perpetuar caso não haja uma estratégia paralela de apoio a esse segmento para o atendimento das novas obrigações legais da atividade.

Quanto ao comportamento institucional e organizacional das entidades representativas da agricultura familiar frente às possíveis consequências da IN51, as respostas indicaram que elas estão trabalhando no sentido de se adaptarem às novas realidades da cadeia leiteira. A resistência às mudanças produzidas pelo ambiente institucional está se arrefecendo em relação a tempos anteriores. A estratégia de cooperação vem sendo incentivada pelas organizações locais. Segundo alguns informantes, essa estratégia organizacional visa minimizar os problemas causados pela especialização da atividade e seleção por critérios de escala dos produtores. Entretanto, quase todos os entrevistados alegaram que mais recentemente as entidades representativas reduziram sua atuação no ambiente institucional da cadeia produtiva do leite. Para boa parte dos informantes qualificados, essa pressão organizacional se deu no início da implementação da IN51 e vem gradativamente perdendo força.

Com base nesses relatos, o futuro da atividade leiteira para a agricultura familiar na região estudada, e muito provavelmente nos demais territórios com relevante produção leiteira, dependerá de diversos fatores, entre eles, a capacidade organizativa, a dedicação à atividade, o tipo de Ater oferecida pelas entidades públicas e privadas e a existência de políticas públicas mais específicas para esse grupo. A maioria dos entrevistados apontou que a IN51 não é um problema quanto a seus patamares de qualidade e necessidade de investimentos, mas sim, pela possível estrutura de governança que ela poderá vir a fortalecer por meio da padronização. Pode-se afirmar que existem diferentes análises sobre o futuro da participação da agricultura familiar na cadeia produtiva do leite no Oeste Catarinense.

Para finalizar, ficou visível que as opiniões dos informantes qualificados diferem em função da posição de interferência no ambiente institucional e do tipo de relação que eles têm com os demais agentes da cadeia. Os representantes de entidades governamentais reproduzem um cenário no qual a IN51 é positiva para todos e que seus aspectos normativos são necessários porque trazem benefícios para a maioria dos participantes da cadeia leiteira. Por outro lado, representantes de entidades próximas à agricultura familiar demonstram preocupação quanto ao futuro e apresentam uma série de condicionantes para a permanência dos produtores nessa atividade, projetando um cenário menos favorável. Por último, os extensionistas preveem um cenário incerto, explicitando a falta de planejamento futuro quanto à realidade da produção leiteira familiar e às exigências do ambiente institucional.

\section{Considerações finais}

Levando-se em consideração todos os aspectos desta investigação, pode-se afirmar que o ambiente institucional, moldado a partir da implantação da IN51, tem influência decisiva na forma de organização e participação da agricultura familiar na cadeia produtiva do leite. O trabalho permitiu perceber que os agricultores familiares e os demais atores envolvidos na cadeia leiteira do Oeste Catarinense (extensionistas, empresários, gestores públicos e representantes sindicais) reconhecem que o ambiente institucional é um forte indutor de mudanças na governança da cadeia produtiva, tanto nas questões relacionadas a formas de produção de leite quanto nas estratégias de organização e acesso a mercados. Com isso, a IN51 é considerada um marco regulatório muito importante na regulação do setor, servindo como "divisor de águas" entre os agricultores que pretendem permanecer na 
atividade e os que gradativamente serão excluídos da produção comercial do leite.

Como consequência da implantação da IN51 para a agricultura familiar, destacam-se os seguintes pontos: a) há um conflito de interesses entre os agentes quanto às consequências geradas pela IN51 sobre a produção e economia familiar; b) a partir da IN51, o ambiente institucional da cadeia produtiva do leite tende a impor restrições e condicionantes para a participação de produção não especializada e com escala insuficiente para cobrir os custos com os investimentos necessários; c) embora a IN51 não apresente nenhum tipo de critério claro para a seleção ou exclusão de produtores de leite, sua implantação tende a contribuir para que a cadeia produtiva se torne mais integrada; d) se os níveis de investimentos (financeiros e humanos) exigidos para uma propriedade de leite se especializar forem altos, poderá haver exclusão de um número significativo de agricultores familiares no médio e longo prazo; e) ainda falta mais conhecimento por parte dos agricultores familiares das novas exigências da IN51, fato que evidencia a existência de assimetria de informação entre os agentes da cadeia produtiva e, consequentemente, comportamentos oportunistas.

A partir dessas conclusões, entende-se que para que a participação da agricultura familiar na cadeia do leite continue tendo a mesma relevância serão necessárias estratégias e políticas públicas de caráter compensatório para minimizar os impactos negativos desse novo ambiente institucional. Entre essas ações, pode-se citar a oferta de linhas de financiamento para a produção sustentável de leite e investimentos em Ater voltados para os agricultores com riscos maiores de exclusão. Outro aspecto nesse sentido é a possibilidade de fomentar processos de cooperação entre pequenos produtores, via experiências de cooperativismo e economia solidária, especialmente no momento de comercialização da produção, gerando lastro nas negociações através da ação coletiva.

\section{Referências bibliográficas}

ALSTON, L. J. A framework for understanding the New Institutional Economics. Dept. Of Economics, University of Illinois, 1999.

BARCELOS, R. M. A Nova Economia Institucional: teoria e aplicações. Brasília/DF. UnB - PET, Departamento de Economia, 2003.

BREDA, N. L. A coordenação da cadeia produtiva do leite no Oeste Catarinense: uma análise da interface agricultor indústria. 2000. Disponível em <http://www.fearp.usp. br/egna/resumos/BredaN.pdf $>$, acessado em 13 fev. 2007.

CLARO, D. P. O Complexo agroindustrial das flores sob a ótica da Economia dos Custos de Transação. In: Caderno de Pesquisa em Administração, São Paulo, vol. 1. 1998.

COASE, R. H. The firm, the market and the law. Chicago: Chicago University Press, 1988.

DÜRR, J. W. Programa Nacional de Melhoria da Qualidade do Leite: Oportunidade única. In: O compromisso com a qualidade do leite no Brasil. Ed. UPF, Passo Fundo/RS, 2004.

EMBRAPA - Empresa Brasileira de Pesquisa Agropecuária Gado de Leite. Disponível em <http:// www.cnpgl.embrapa.br/> acessado em 08.02.2010.

FAVARETO, A. A racionalização da vida rural. Revista Estudos, sociedade e agricultura, vol. 14, n. 1, 2006.

FIGUERA, S. R. e BELIK, W. Transformação no Elo Industrial da Cadeia Produtiva do Leite. Revista Cadernos de Debate, Núcleo de Estudos e Pesquisas em Alimentos da UNICAMP Vol. VII / 1999. Campinas/SP. 1999.

GUILHOTO, J., ICHIARA, S., SILVEIRA, F. G., DINIZ, B. C. e AZZONI, C. A importância da agricultura familiar no Brasil e em seus estados. Brasília: NEAD, 2007.

INSTITUTO BRASILEIRO DE GEOGRAFIA E ESTATÍSTICA - IBGE. Malha Municipal Digital, 1999. Disponível <http://www.ibge.gov.br>, acesso em 10.10.2009.

MELLO, M. A. e FERRARI, D. L. A base agrícola do Oeste Catarinense, a importância e o perfil da atividade leiteira. In: TESTA, V. M. et. al. A escolha da trajetória da produção de leite como estratégia de desenvolvimento do Oeste Catarinense. Florianópolis: SAR, p. 15-34, 2003. 
NORDER, L. A. C. Mercantilização da agricultura e desenvolvimento territorial. In: SCHINEIDER, S. (Org.). A diversidade da agricultura familiar. Porto Alegre: UFRGS, 2006.

NORTH, D. Institutions, institutional change and economic performance. Cambridge: Cambridge University Press, 1991.

OLIVEIRA, L. F. T. Ambiente institucional e produção leiteira: um estudo de caso na região oeste catarinense a partir da introdução da IN51. Viçosa: UFSM, 2008. Dissertação (Mestrado em Extensão Rural). Universidade Federal de Santa Maria, 2008.

SILVA, S. P. Políticas públicas e agricultura familiar: uma abordagem territorial do PRONAF no Médio Jequitinhonha. Viçosa: UFV, 2008. Dissertação (Mestrado em Economia). Universidade Federal de Viçosa, 2008.

SILVA, S. P. Incidência territorial e arranjos institucionais do PRONAF: uma análise no Médio Jequitinhonha - MG. In: Anais do 47ํㅡㄹ Congresso da Sober, Porto Alegre, 2009.

SOUZA, C. Estado da arte da pesquisa em políticas públicas. In: HOCHMAN, G., ARRETCHE, M. e
MARQUES, E. (Org.) Políticas públicas no Brasil. Rio de Janeiro: FIOCRUZ, 2007.

TESTA, V. M. A escolha da trajetória da produção de leite como estratégia de desenvolvimento do Oeste Catarinense. Florianópolis: SAR, 2003.

WILLIANSON, O. E. Las instituciones económicas del capitalismo. México: Fondo de Cultura Econômica, 1989.

WILLIANSON, O. E. The New Institutional Economics: taking stock, looking ahead. Journal of Economic Literature, vol. XXXVIII, 2000.

YIN, R. K. Estudo de Caso: planejamento e métodos. Porto Alegre: Bookman, 2005.

ZILBERSZTAJN, D. Estrutura de governança e coordenação do agrobusiness: uma aplicação da nova economia das instituições. São Paulo: USP, 1995. Tese (Doutorado em Economia). Universidade de São Paulo, 1995.

ZILBERSZTAJN, D. Conceito geral, evolução e apresentação dos sistemas agroindustrial. In: ZILBERSZTAJN, D. e NEVES, M. F. Economia e gestão de negócios agroalimentares. São Paulo: Pioneira. 2000. 